\title{
PENGARUH PROFESIONALISME, KECERDASAN INTELEKTUAL DAN BUDAYA ORGANISASI TERHADAP EFEKTIVITAS KERJA PEGAWAI DI BALAI DIKLAT PUPR WILAYAH I MEDAN
}

\author{
${ }^{1}$ Andi Kuncoro, ${ }^{2}$ Malik Assalih Harahap, ${ }^{3}$ Yanjahuddin, ${ }^{4}$ Muhammad Asrin Batubara, ${ }^{5}$ Heni Marito Harahap \\ ${ }_{1,2,3,4,5}$ Universitas Islam Sumatera Utara \\ landi.kuncoro@gmail.com, ${ }^{2}$ malik.assalih@gmail.com, ${ }^{3}$ yanjahuddin.mm@gmail.com, ${ }^{4}$ mhd.asrin@gmail.com, \\ ${ }^{5}$ henimarito.hrp@gmail.com
}

\begin{abstract}
The formulation of the problem in this study is whether there is an effect of professionalism on employee work effectiveness. Is there an effect of intellectual intelligence on employee work effectiveness. Is there an influence of organizational culture on employee work effectiveness. Is there any influence of professionalism, intellectual intelligence and organizational culture on the work effectiveness of the employees of the PUPR Region I Medan Training Center. The purpose of this study was to determine and analyze the effect of professionalism on employee work effectiveness. The influence of intellectual intelligence on employee work effectiveness. The influence of organizational culture on employee work effectiveness. The influence of professionalism, intellectual intelligence and organizational culture on the work effectiveness of the employees of the PUPR Region I Medan Training Center. The sample in this study amounted to 53 people. The data analysis technique used in this research is descriptive analysis and multiple linear regression analysis. The results of this study explain that the intellectual intelligence variable has a positive and significant effect on employee work effectiveness. Professionalism and organizational culture variables do not have a positive and significant effect on employee work effectiveness. The variables of professionalism, intellectual intelligence and organizational culture have a positive and significant effect on the work effectiveness of the employees of the PUPR Region I Medan Training Center.
\end{abstract}

Keywords: Professionalism, intellectual intelligence, organizational culture, work effectiveness

\begin{abstract}
ABSTRAK : Rumusan masalah dalam penelitian ini adalah apakah ada pengaruh profesionalisme terhadap efektivitas kerja pegawai. Apakah ada pengaruh kecerdasan intelektual terhadap efektivitas kerja pegawai. Apakah ada pengaruh budaya organisasi terhadap efektivitas kerja pegawai. Apakah ada pengaruh profesionalisme, kecerdasan intelektual dan budaya organisasi terhadap efektivitas kerja pegawai Balai Diklat PUPR Wilayah I Medan. Tujuan penelitian ini adalah untuk mengetahui dan menganalisis pengaruh profesionalisme terhadap efektivitas kerja pegawai. Pengaruh kecerdasan intelektual terhadap efektivitas kerja pegawai. Pengaruh budaya organisasi terhadap efektivitas kerja pegawai. Pengaruh profesionalisme, kecerdasan intelektual dan budaya organisasi terhadap efektivitas kerja pegawai Balai Diklat PUPR Wilayah I Medan. Sampel dalam penelitian ini berjumlah 53 orang. Teknik analisis data yang digunakan dalam penelitian ini adalah analisis deskriptif dan analisis regresi linier berganda. Hasil penelitian ini menjelaskan bahwa variabel kecerdasan intelektual berpengaruh positif dan signifikan terhadap efektivitas kerja pegawai. Variabel profesionalisme dan budaya organisasi tidak berpengaruh positif dan signifikan terhadap efektivitas kerja pegawai. Variabel profesionalisme, kecerdasan intelektual dan budaya organisasi berpengaruh positif dan signifikan terhadap efektivitas kerja pegawai Balai Diklat PUPR Wilayah I Medan.
\end{abstract}

Kata Kunci: Profesionalisme, Kecerdasan intelektual, Budaya organisasi, Efektifitas Kerja

\section{Pendahuluan}

Setiap organisasi baik swasta maupun pemerintah mempunyai tujuan yang hendak dicapai. Organisasi yang siap bersaing harus memiliki manajemen yang efektif karena tujuan organisasi akan lebih mudah dicapai. 
Manajemen adalah ilmu dan seni yang mengatur proses pemanfaatan sumber daya manusia dan sumber-sumber daya lainnya secara efektif dan efisien untuk mencapai suatu tujuan tertentu.

Suatu cara penyelesaian pekerjaan tepat pada waktu yang telah ditentukan, merupakan suatu bentuk efektivitas kerja, pelaksanaan suatu tugas ditandai baik atau tidak, sangat tergantung pada penyelesaian tugas tersebut, bagaimana cara melaksanakannya, dan berapa biaya yang dikeluarkan untuk itu. Hal ini lebih menekankan pada penyelesaian tugas yang telah ditentukan sebelumnya. Sarwoto (2000:126) mengistilahkan efektivitas dengan "berhasil guna" yaitu pelayanan yang baik corak dan mutunya benar-benar sesuai kebutuhan dalam pencapaian tujuan organisasi.

Berdasarkan penelusuran studi empiris, penulis mengemukakan bahwa variabel pertama yang teridentifikasi mempengaruhi efektivitas kerja pegawai adalah profesionalisme. Menurut Siagian (2000:163), menyatakan bahwa yang dimaksud dengan profesionalisme adalah keandalan dalam pelaksanaan tugas, sehingga terlaksana dengan mutu tinggi, waktu yang tepat, cermat, dan dengan prosedur yang mudah dipahami dan diikuti oleh orang lain. Terbentuknya aparatur profesional menurut pendapat tersebut memerlukan pengetahuan dan ketrampilan khusus yang dibentuk melalui pendidikan dan pelatihan sebagai instrument pemutakhiran.

Variabel profesionalisme ini pernah dijadikan sebagai salah satu variabel dalam sebuah penelitian diantaranya oleh Ratna Andita Dewi di tahun 2016. Dimana pada penelitian tersebut menyimpulkan bahwa variabel profesionalisme memiliki pengaruh terhadap efektivitas sistem pengendalian internal perusahaan. Begitu juga penelitian yang dilakukan oleh Abu Hanifah di tahun 2016 juga, dimana variabel profesionalisme secara parsial berpengaruh terhadap kinerja pegawai. Artinya pada penelitian keduanya variabel profesionalisme memiliki pengaruh terhadap variabel terikatnya.

Fenomena yang terjadi di lingkungan Balai Diklat Pekerjaan Umum dan Perumahan Rakyat Wilayah I Medan, diketahui masih lemahnya sikap profesionalisme pegawai dalam memahami peran dan tanggung jawabnya sebagai seorang pegawai Balai Diklat PUPR Wilayah I Medan.
Variabel berikutnya yang mempengaruhi efektivitas kerja di Balai Diklat Pekerjaan Umum dan Perumahan Rakyat Wilayah I Medan adalah kecerdasan intelektual. Menurut Armansyah (2002), menyatakan bahwa IQ (Intelligence Quotient) adalah tolok ukur dari kepintaran seseorang, $I Q$ bukan merupakan satu-satunya indikator kesuksesan seseorang. $I Q$ hanya memberikan sedikit indikasi mengenai taraf kecerdasan seseorang dan tidak mengambarkan kecerdasaan seseorang secara keseluruhan. Seseorang yang ber- $I Q$ tinggi, belum tentu mutlak akan berhasil memecahkan permasalahan-permasalahan di dalam dunia kerja yang kompleks, tetapi perlu adanya sisi cerdas lain dari pegawai tersebut.

Beberapa penelitian mengatakan bahwa kecerdasan intelektual merupakan variabel yang dapat memengaruhi efektivitas kerja pegawai secara langsung, diantaranya penelitian dari Tirta Sati Ayu (2018). Hasil penelitian ini menyatakan bahwa kecerdasan intelektual berpengaruh positif dan signifikan. Fenomena yang terjadi di Balai Diklat Pekerjaan Umum dan Perumahan Rakyat Wilayah I Medan diantaranya masih relatif lambatnya kemampuan pegawai dalam penyelesaian pekerjaan dan masih belum sesuainya pekerjaan yang dikerjakan terhadap apa yang sudah direncanakan sebelumnya.

Variabel yang terakhir yang mempengaruhi efektivitas kerja pegawai adalah budaya organisasi. Menurut Wibowo (2011:55) bahwa budaya organisasi adalah filosofi dasar organisasi yang memuat keyakinan, normanorma, dan nilai-nilai bersama yang menjadi karakteristik inti tentang bagaimana cara melakukan sesuatu dalam organisasi. Sehingga, dengan adanya keyakinan inti bersama yang dijadikan pedoman bersama diharapkan mampu mengarahkan anggota organisasi untuk bertindak lebih efektif dalam pencapain tujuan organisasi.

Beberapa penelitian terdahulu telah membuktikan bahwa budaya organisasi memiliki pengaruh yang berarti terhadap efektivitas kerja pegawai yakni oleh Armansyah di tahun 2016. Pada hasil penelitian mereka dapat disimpulkan bahwa budaya organisasi dapat meningkatkan efektivitas kerja pegawai sehingga dapat terwujudnya tujuan perusahaan atau organisasi.

Adapun yang menjadi fenomena yang terjadi terkait tentang budaya organisasi di Balai Diklat Pekerjaan Umum dan Perumahan 
Rakyat Wilayah I Medan bahwa kurangnya keterlibatan pegawai dalam menyusun kebijakan strategis perusahaan dan masih rendahnya pemahaman pegawai terhadap visi dan misi perusahaan.

\subsection{Batasan Masalah}

Agar permasalahan yang dikaji terarah maka permasalahan dibatasi sebagai berikut. Penelitian ini hanya membahas profesionalisme, kecerdasan intelektual, budaya organisasi dan efektivitas kerja pegawai Balai Diklat PUPR Wilayah I Medan.

\subsection{Hioptesis}

Berdasarkan rumusan masalah tujuan penelitian, kajian teori, dan kerangka konseptual yang telah dikemukakan diatas, maka rumusan hipotesis penelitian ini dapat dirumuskan sebagai berikut:

1) Profesionalisme berpengaruh signifikan terhadap efektivitas kerja pegawai di Balai Diklat PUPR Wilayah I Medan.

2) Kecerdasan intelektual berpengaruh signifikan terhadap efektivitas kerja pegawai di Balai Diklat PUPR Wilayah I Medan.

3) Budaya organisasi berpengaruh signifikan terhadap efektivitas kerja pegawai di Balai Diklat PUPR Wilayah I Medan.

4) Profesionalisme, kecerdasan intelektual, dan budaya organisasi secara bersama-sama berpengaruh signifikan terhadap efektivitas kerja di Balai Diklat PUPR Wilayah I Medan.

\subsection{Tujuan Penelitian}

Berdasarkan rumusan masalah penelitian sebagaimana diuraikan di atas, maka tujuan yang akan dicapai dalam penelitian ini yaitu untuk menganalisis:

1) Pengaruh profesionalisme terhadap efektivitas kerja pegawai di Balai Diklat PUPR Wilayah I Medan.

2) Pengaruh kecerdasan intelektual terhadap efektivitas kerja pegawai pegawai di Balai Diklat PUPR Wilayah I Medan.

3) Pengaruh budaya organisasi terhadap efektivitas kerja pegawai di Balai Diklat PUPR Wilayah I Medan.

4) Pengaruh profesionalisme, kecerdasan intelektual dan budaya organisasi terhadap efektivitas kerja pegawai di Balai Diklat PUPR Wilayah I Medan.

\section{Metode Penelitian}

\subsection{Populasi dan Sampel}

Populasi merupakan subjek penelitian, dimana pegawai yang akan dikenai perilaku atau dapat dikatakan sebagai keseluruhan objek penelitian yang akan diteliti. Maka yang menjadi populasi dalam penelitian ini adalah pegawai di Balai Pendidikan dan Pelatihan Pekerjaan Umum dan Perumahan Rakyat Wilayah I Medan yang berjumlah 55 orang dengan rincian sebagai berikut.

Menurut Sugiyono (2014:78), teknik sampling merupakan teknik pengambilan sampel, sedangkan sampel adalah sebagian dari jumlah dan karanteristik yang dimiliki oleh populasi.

Dengan teknik penarikan sampel secara total sampling, maka sampel dalam penelitian ini adalah 53 orang pegawai di Balai Pendidikan dan Pelatihan Pekerjaan Umum dan Perumahan Rakyat Wilayah I Medan (1 orang pimpinan tertinggi dan peneliti tidak dilakukan penelitian).

\subsection{Uji Normalitas}

Pengujian normalitas data bertujuan untuk melihat normal tidaknya sebaran data yang akan dianalisis. Model regresi yang baik adalah distribusi normal atau mendekati normal. Untuk melihat normalitas data ini digunakan pendekatan grafik yaitu Normality Probability Plot. Jadi uji normalitas bukan dilakukan pada masing-masing variabel tetapi pada nilai residualnya. Sering terjadi kesalahan yang jamak yaitu bahwa uji normalitas dilakukan pada masing-masing variabel. Hal ini tidak dilarang tetapi model regresi memerlukan normalitas pada nilai residualnya bukan pada masing-masing variabel penelitian.

Deteksi normalitas dengan melihat penyebaran data (titik) pada sumbu diagonal dari grafik. Menurut Santoso (2004:214), dasar pengambilan keputusan adalah:

a. Jika data menyebar disekitar garis diagonal dan mengikuti arah garis diagonal, maka model regresi memenuhi asumsi normalitas.

b. Jika data menyebar jauh dari garis diagonal dan atau tidak mengikuti arah garis diagonal, maka model regresi tidak memenuhi asumsi normalitas. 


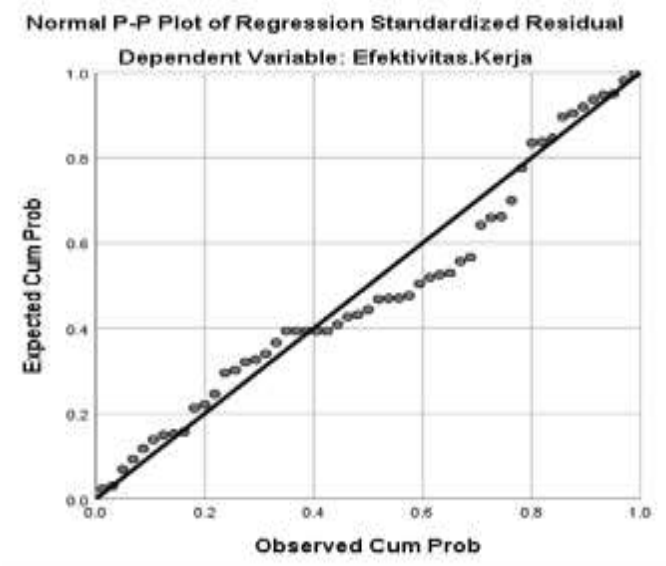

Gambar 1. Normalitas Data

Pada output SPSS seperti gambar diatas diketahui bagian normal P-P Plot of Regresion Standardized Residual, dapat dijelaskan bahwa

\section{Coefficients $^{\mathrm{a}}$}

Tabel 1. Uji Multikolinearitas

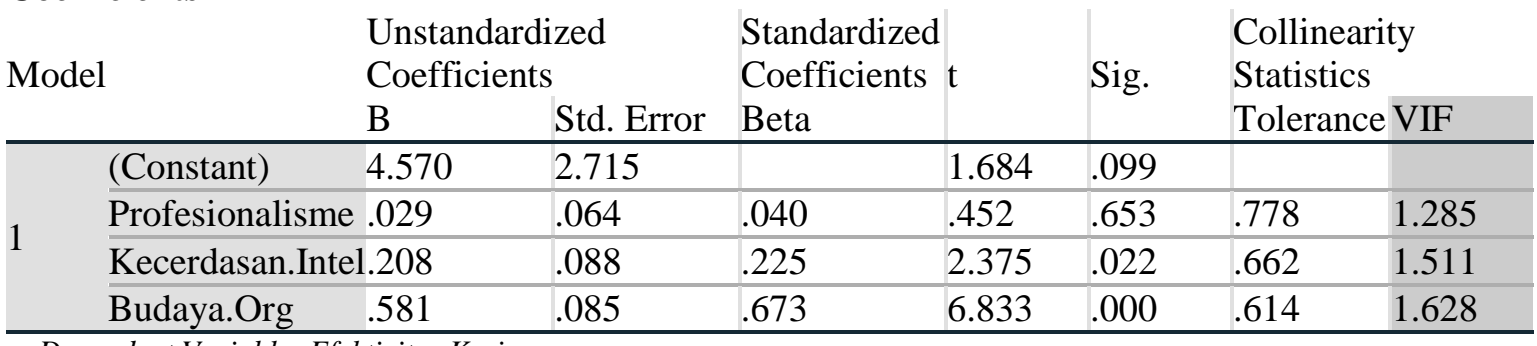

Berdasarkan nilai hasil perhitungan dengan SPSS diperoleh data nilai VIF sebesar 1.285, 1.511 dan 1.628 dengan nilai toleransi 0.778 , 0.662 , dan 0.614 , hal ini menunjukkan adanya korelasi yang cukup kuat antara sesama variabel bebas, dimana semua angka VIF berada dibawah 5, hal ini menunjukan tidak terjadi multikolinearitas.

\subsection{Uji Heterokedastisitas}

Pengujian heteroskedastisitas bertujuan untuk melihat apakah dalam sebuah model regresi terjadi ketidaksamaan varians dari residual yang merupakan suatu pengamatan ke pengamatan yang lainnya. Jika varians dari residual yang merupakan suatu pengamatan ke pengamatan yang lain bernilai tetap, maka hasil data disebut homoskedastisitas dan jika varians berbeda atau bernilai tidak tetap maka disebut heteroskedastisitas. Model regresi yang baik adalah model yang bernilai tetap atau homoskedastisitas atau tidak terjadi heteroskedastisitas.

Deteksi heteroskedastisitas dilakukan dengan cara melihat ada tidaknya pola tertentu pada data yang diolah. Menurut Santoso data-data (titik-titik) cenderung lurus mengikuti garis diagonal sehingga data dalam penelitian ini cenderung berdistribusi normal.

\subsection{Uji Multikolinearitas}

Pengujian multikolinearitas dilakukan untuk melihat apakah pada model regresi ditemukan adanya korelasi antara variabel bebas. Jika terjadi korelasi, maka dinamakan terdapat problem multikolinearitas. Cara mendeteksinya adalah dengan melihat nilai Variance Inflation Factor (VIF). Menurut Santoso (2004:203), pada umumnya jika VIF lebih besar dari 5, maka variabel bebas tersebut mempunyai persoalan multikolinearitas dengan variabel bebas lainnya.
(2004:208), dasar pengambilan keputusannya adalah:

a. Jika pola tertentu seperti titik-titik yang ada membentuk suatu pola tertentu yang teratur, maka terdapat situasi heteroskedastisitas.

b. Jika tidak ada pola yang jelas, serta titik-titik menyebar diatas dan dibawah angka nol pada sumbu Y, maka tidak terjadi heteroskedastisitas.

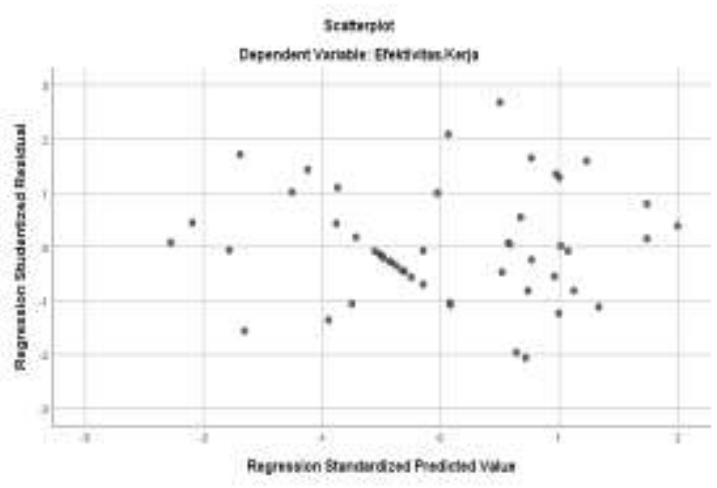

Gambar 2. Uji Heteroskedastitas

Pola Scatterplot seperti pada gambar diatas, terlihat titk-titik menyebar secara acak, tidak membentuk sebuah pola tertentu yang jelas, serta tersebar baik diatas maupun dibawah 
angka nol pada sumbu Y. Hal ini berarti tidak terjadi heteroskedastisitas pada model regresi, sehingga model regresi layak dipakai.

\section{Analisa dan Evaluasi}

\subsection{Regeresi Linier Berganda}

Teknik analisis data yang digunakan adalah regresi linier berganda (multiple linier regression method), untuk mempermudah dalam evaluasi data ini, maka penulis mencari nilai-nilai yang dibutuhkan dengan menggunakan perangkat lunak komputer yaitu program SPSS dengan hasil data seperti pada tabel diatas maka diperoleh hasil sebagai berikut:

Tabel 1. Hasil Regresi Linear Berganda

\section{Coefficients $^{\mathrm{a}}$}

\begin{tabular}{|c|c|c|c|c|c|c|c|c|}
\hline & \multirow[t]{2}{*}{ Model } & \multicolumn{2}{|c|}{$\begin{array}{c}\text { Unstandardized } \\
\text { Coefficients }\end{array}$} & \multirow{2}{*}{$\begin{array}{l}\text { Standardized } \\
\text { Coefficients } \\
\text { Beta }\end{array}$} & \multirow[t]{2}{*}{$\mathrm{t}$} & \multirow[t]{2}{*}{ Sig. } & \multicolumn{2}{|c|}{$\begin{array}{c}\text { Collinearity } \\
\text { Statistics }\end{array}$} \\
\hline & & B & Std. Error & & & & Tolerance & VIF \\
\hline \multirow{4}{*}{1} & (Constant) & 4.570 & 2.715 & & 1.684 & .099 & & \\
\hline & Profesionalisme & .029 & .064 & .040 & .452 & .653 & .778 & 1.285 \\
\hline & Kecerdasan.Intel & .208 & .088 & .225 & 2.375 & .022 & .662 & 1.511 \\
\hline & Budaya.Org & .581 & .085 & .673 & 6.833 & .000 & .614 & 1.628 \\
\hline
\end{tabular}

a. Dependent Variable: Efektivitas.Kerja

Persamaan regresi linier berganda dapat diperoleh dari Tabel 1, sebagai berikut :

$$
Y=4,570+0,029 X_{1}+0,208 X_{2}+0,581 X_{3}+
$$

$\varepsilon$

Persamaan diatas dijelaskan bahwa koefesien $\mathrm{X}_{1}$ (profesionalisme) mempunyai nilai positif yaitu 0,029 , hal ini menunjukan bahwa variabel profesionalisme mempunyai pengaruh positif terhadap efektivitas kerja pegawai. Sementara itu pada persamaan diatas bahwa koefesien $\mathrm{X}_{2}$ (kecerdasan intelektual) memiliki nilai positif yaitu 0,208 . Hal ini menunjukan bahwa variabel kecerdasan intelektual mempunyai pengaruh positif terhadap efektivitas kerja pegawai. Sedangkan berdasarkan persamaan diatas bahwa koefesien $\mathrm{X}_{3}$ (budaya organisasi) memiliki nilai positif yaitu 0,581 . Hal ini menunjukan bahwa variabel budaya organisasi mempunyai pengaruh positif terhadap efektivitas kerja pegawai di Balai Diklat PUPR Wilayah I Medan.

Hal ini berarti semua variabel profesionalisme, kecerdasan intelektual dan budaya organisasi yang saat ini berlaku di Balai Diklat PUPR Wilayah I Medan telah mampu meningkatkan efektivitas kerja pegawai walaupun nilainya tersebut bervariasi.

\subsection{Pengujian Simultan (Uji F)}

Hasil pengujian hipotesis berpengaruh secara simultan antara profesionalisme, kecerdasan intelektual dan budaya organisasi terhadap efektivitas kerja pegawai dapat dilihat pada tabel dibawah ini.

ANOVA $^{\mathrm{a}}$

Tabel 2. Hasil Uji F

\begin{tabular}{llllllll} 
Model & & Sum of Squares & df & Mean Square & F & Sig. \\
\hline \multirow{3}{*}{1} & Regression & 315.173 & 3 & 105.058 & 39.577 & $.000^{\mathrm{b}}$ \\
\cline { 2 - 7 } & Residual & 130.072 & 49 & 2.655 & & \\
\cline { 2 - 6 } & Total & 445.245 & 52 & & & \\
\hline
\end{tabular}

a. Dependent Variable: Efektivitas.Kerja

b. Predictors: (Constant), Budaya.Org, Profesionalisme, Kecerdasan.Intel

Pada tabel diatas terlihat bahwa nilai $\mathrm{F}$ hitung adalah 39,577 dan nilai signifikansi 0,000 . Dengan derajat bebasnya yaitu $\mathrm{df}_{1}=\mathrm{k}-$ $1=4-1=3$ dan $\mathrm{df}_{2}=\mathrm{N}-\mathrm{k}=53-4=49$, maka nilai $\mathrm{F}$-tabel dengan tingkat kepercayaan $95 \%(\alpha: 0,05)$ adalah $\mathbf{2 , 7 9}$.
Oleh karena itu nilai F-hitung > F-tabel $(39,577>2,79)$ dan dengan nilai signifikansi $0,000<0,05$ maka Ha diterima dan Ho ditolak berarti hipotesis dalam penelitian ini yaitu bahwa profesionalisme, kecerdasan intelektual dan budaya organisasi secara simultan berpengaruh signifikan terhadap efektivitas 
kerja pegawai dalam bekerja di Balai Diklat PUPR Wilayah I Medan.

\subsection{Pengujian Parsial (Uji t)}

1) Pengaruh Profesionalisme Terhadap Efektivitas Kerja
Untuk mengetahui secara parsial pengaruh profesionalisme terhadap produktivitas kerja pegawai dapat dilihat pada tebel multikolinearitas. Dengan derajat bebas pengujian (df) adalah $\mathrm{N}-\mathrm{k}=53-4=49$. Maka nilai t-tabel pada tingkat kepercayaan $95 \%(\alpha$ : 0,05 ) adalah $\mathbf{2 , 0 0 9}$.

\section{Coefficients $^{\mathrm{a}}$}

\begin{tabular}{|c|c|c|c|c|c|c|c|}
\hline \multirow[t]{2}{*}{ Model } & \multicolumn{2}{|c|}{$\begin{array}{l}\text { Unstandardized } \\
\text { Coefficients }\end{array}$} & \multirow{2}{*}{$\begin{array}{c}\text { Standardized } \\
\text { Coefficients } \\
\text { Beta }\end{array}$} & \multirow[t]{2}{*}{$\mathrm{t}$} & \multirow[t]{2}{*}{ Sig. } & \multicolumn{2}{|c|}{$\begin{array}{l}\text { Collinearity } \\
\text { Statistics }\end{array}$} \\
\hline & $\mathrm{B}$ & Std. Error & & & & Tolerance & VIF \\
\hline Profesionalisme & .029 & .064 & .040 & .452 & .653 & .778 & 1.285 \\
\hline
\end{tabular}

a. Dependent Variable: Efektivitas. Kerja

Sumber: Data diolah dengan SPSS, Tahun 2020

Berdasarkan tabel tersebut diperoleh nilai t-hitung sebesar 0,452, maka nilai t-hitung $<\mathrm{t}$ tabel $(0,452<2,009)$, maka dapat disimpulkan Ho diterima dan Ha ditolak, yang artinya variabel profesionalisme secara parsial tidak ada pengaruh signifikan efektivitas kerja pegawai dalam bekerja di Balai Diklat PUPR Wilayah I Medan.
2) Pengaruh Kecerdasan Inetelektual Terhadap Efektivitas Kerja

Untuk mengetahui secara parsial pengaruh kecerdasan intelektual terhadap produktivitas kerja pegawai dapat dilihat pada tebel multikolinearitas. Dengan nilai t-tabel yang sama dengan data diatas sebesar $\mathbf{2 , 0 0 9}$ pada tingkat kepercayaan $95 \%(\alpha: 0,05)$.

\section{Coefficients $^{\mathrm{a}}$}

\begin{tabular}{|c|c|c|c|c|c|c|c|}
\hline \multirow{2}{*}{ Model } & \multicolumn{2}{|c|}{$\begin{array}{l}\text { Unstandardized } \\
\text { Coefficients }\end{array}$} & \multirow{2}{*}{$\begin{array}{l}\text { Standardized } \\
\text { Coefficients } \\
\text { Beta }\end{array}$} & \multirow[t]{2}{*}{$\mathrm{t}$} & \multirow[t]{2}{*}{ Sig. } & $\begin{array}{l}\text { Collinearit } \\
\text { Statistics }\end{array}$ & \\
\hline & $\mathrm{B}$ & Std. Error & & & & Tolerance & VIF \\
\hline Kecerdasan.Intel & .208 & .088 & .225 & 2.375 & .022 & .662 & 1.511 \\
\hline
\end{tabular}

a. Dependent Variable: Efektivitas.Kerja

Sumber: Data diolah dengan SPSS, Tahun 2020

Dari hasil perhitungan SPSS maka nilai thitung sebesar 2,375, jadi nilai t-hitung $>$ t-tabel $(2,375>2,009)$, maka dapat disimpulkan Ha diterima dan Ho ditolak, yang artinya variabel kecerdasan intelektual secara parsial ada pengaruh signifikan efektivitas kerja pegawai dalam bekerja di Balai Diklat PUPR Wilayah I Medan.

3) Pengaruh Budaya Organisasi Terhadap Efektivitas Kerja

Variabel ketiga adalah menguji budaya organisasi terhadap produktivitas kerja pegawai dapat dilihat pada tebel multikolinearitas. Pada tingkat kepercayaan $95 \%(\alpha: 0,05)$ maka nilai t-tabel sebesar 2,009.

\section{Coefficients $^{\mathrm{a}}$}

\begin{tabular}{|c|c|c|c|c|c|c|c|}
\hline \multirow{2}{*}{ Model } & \multicolumn{2}{|c|}{$\begin{array}{l}\text { Unstandardized } \\
\text { Coefficients }\end{array}$} & \multirow{2}{*}{$\begin{array}{l}\text { Standardized } \\
\text { Coefficients } \\
\text { Beta } \\
\end{array}$} & \multirow{2}{*}{$\mathrm{t}$} & \multirow[t]{2}{*}{ Sig. } & \multicolumn{2}{|c|}{$\begin{array}{l}\text { Collinearity } \\
\text { Statistics }\end{array}$} \\
\hline & B & Std. Error & & & & Tolerance & VIF \\
\hline Budaya.Org & .581 & .085 & .673 & 6.833 & .000 & .614 & 1.628 \\
\hline
\end{tabular}


Dari tabel diatas dapat dijelaskan bahwa dengan nilai t-hitung 6,833 maka t-hitung $>\mathrm{t}$ tabel $(6,833>2,009)$, dapat disimpulkan $\mathrm{Ha}$ diterima dan Ho ditolak, yang artinya variabel budaya organisasi secara parsial ada pengaruh signifikan efektivitas kerja pegawai dalam bekerja di Balai Diklat PUPR Wilayah I Medan.

Model Summary

\begin{tabular}{lllll} 
Model & $\mathrm{R}$ & $\mathrm{R}$ Square & Adjusted R Square & $\begin{array}{l}\text { Std. Error of the } \\
\text { Estimate }\end{array}$ \\
\hline 1 & $.841^{\mathrm{a}}$ & .708 & .690 & 1.629
\end{tabular}

Maka pada tabel diatas menunjukan nilai Adjusted $\mathrm{R}^{2}$ adalah $69,0 \%$ variabel efektivitas kerja pegawai di Balai Diklat PUPR Wilayah I Medan dapat dijelaskan oleh variabel profesionalisme, kecerdasan intelektual dan budaya organisasi sedangkan sisanya tidak dilakukan dalam penelitian ini. Dengan kata lain variabilitas Kinerja Pegawai Di Balai Diklat Pupr Wilayah I Medan dapat diterangkan Oleh Variabel profesionalisme, Kecerdasan Intelektual dan Budaya Organisasi sebesar 69\%, Sedangkan Sisanya Sebesar 31\% disebabkan Oleh variabel-variabel lain diluar model penelitian ini.

\section{Kesimpulan}

Berdasarkan pada analisis dan evaluasi data pada bab sebelumnya, maka dapat ditarik kesimpulan sebagai berikut :

1) Variabel kepemimpinan berpengaruh positif dan signifikan terhadap kinerja pegawai Dinas Pendidikan Kabupaten Batu Bara dengan nilai $t_{\text {hitung }}>t_{\text {tabel }}(2.046>2,013)$ dan nilai signifikasi $0,049<0,05$.

2) Variabel kematangan pegawai berpengaruh positif dan signifikan terhadap kinerja pegawai Dinas Pendidikan Kabupaten Batu Bara dengan nilai $t_{\text {hitung }}>t_{\text {tabel }}(3.196>$ $2,013)$ dan nilai signifikasi $0,003<0,05$.

3) Variabel lingkungan kerja berpengaruh positif dan signifikan terhadap kinerja pegawai Dinas Pendidikan Kabupaten Batu Bara dengan nilai $t_{\text {hitung }}>t_{\text {tabel }}(4.025>$ $2,013)$ dan nilai signifikasi $0,000<0,05$.

4) Variabel kepemimpinan, kematangan pegawai dan lingkungan kerja berpengaruh positif dan signifikan terhadap kinerja pegawai Dinas Pendidikan Kabupaten Batu

\subsection{Pengujian Koefisien Determinasi}

Uji determinan adalah untuk mengetahui seberapa besar pengaruh variabel independen terhadap variabel dependen. Untuk melihat hasil uji determinan maka dapat diketahui nilai $\mathrm{R}$ Square atau koefesien determinasi dan dapat dilihat dibawah ini. Untuk variabel independen lebih dari dua sebaiknya menggunakan nilai Adjusted $\mathrm{R}^{2}$.

del Summary

Bara dengan nilai $F_{\text {hitung }}>F_{\text {tabel }}(19.336>$ 2,66) dan nilai signifikasi $0,000<0,05$.

5) Pengaruh variabel kepemimpinan, kematangan pegawai dan lingkungan kerja terhadap kinerja pegawai Dinas Pendidikan Kabupaten Batu Bara sebesar 63\%, sedangkan sisanya sebesar 37\% dipengaruhi oleh faktor-faktor lain yang tidak diteliti.

\section{DAFTAR PUSTAKA}

Adlina Yulianti Dyah Suryadiningrum (2014), Pengaruh Kematangan Karyawan Terhadap Kinerja Karyawan Dengan Komitmen Organisasional Sebagai Variabel Moderating (Studi Pada Karyawan Himalaya Garment Kota Malang), Jurnal administrasi Bisnis, Vol.1 No. 1.

Andari (2016), Pengaruh Kepemimpinan Dan Lingkungan Kerja Terhadap Kinerja Pegawai Dinas Koperasi Dan UMKM Provinsi Banten, Jurnal Sains Manajemen, Volume.2 No.2 Juni 2016

Arikunto, Suharsismi. (2011). Prosedur Penelitian Suatu Pendekatan Praktek. Jakarta: Rineka Cipta.

Colquitt, J. A., LePine, J. A., and Wesson., (2009) Organizational Behavior: Improving Performance and Commitment in the Workplace, New York, McGraw Hill, pp. 37

Cross, T.M dan Lynch. R.R. (2011). Peniliaian dan Evaluasi Kinerja: Konsep dan Praktik. Jakarta. Penerbit Ghalia Indonesia

Dessler, Gary. (2013). Manajemen Sumber Daya Manusia (Jilid I). Jakarta : Indeks.

Dewa Putu Meles Arta (2015), Pengaruh Motivasi dan Lingkungan Kerja Terhadap Kinerja PNS Pada KPP Bea dan Cukai Tipe 
Madya Pabean Ngurah Rai Kabupaten Badung, Juima,Vol, 5 No. 1 Maret 2015

Fauzi, A. (2013). Pengaruh Kepemimpinan, Kecerdasan Individuonal dan Motivasi terhadap Kinerja Guru di SMA. Jurnal Manajemen Pendidikan Vol 1, No 1

Gibson, James L., Ivancevich, John M., Donnely, James H., and Konopaske (2009) Organizations: Behavior, Structure, Processes,New York, McGraw Hill

Goleman, D. (2014). Emotional Entellegent. PT. Gramedia Pustaka Utama, Jakarta

Hasibuan, Malayu S. P. (2013). Manajemen Sumber Daya Manusia. Edisi Revisi Jakarta: PT. Bumi Aksara.

Mangkunegara, Anwar, Prabu. (2009). Evaluasi Kinerja SDM, Cetakan 4, Bandung : Refika Aditama

Mangkuprawira, Sjafri. (2014). Manajemen Sumber Daya Manusia Strategik. Cetakan ketiga, Penerbit Ghalia Indonesia

Murphy, S. E., and Pirozzolo, F. J., (2011) Multi Journal ple Intelligences and Leadership, New Jersey, Lawrence Erlbaum

Ridwan. (2013). Skala Pengukuran VariabelVariabel Bandung : Alfabeta

Robbins S.P \& Judge,T.A. 2013. Perilaku Organisasi. Buku 1 Edisi 12. Terjemahan Diana Angelica. Penerbit Salemba Empat. Jakarta.

Robbins, Stephen P. (2006). Perilaku Organisasi. Edisi kesepuluh. Jakarta: Indeks Kelompok Gramedia.

Rush, Michael dan Althoff, Phillip. (2009). Pengantar Sosiologi Politik. Jakarta: PT. Raja Grafindo Persada.

Samsudin, Sadili. (2009). Manajemen Sumber Daya Manusia. Bandung: CV. Pustaka Setia.

Sedarmayanti. (2014). Good Governance (Kepemerintahan Yang Baik), Bandung : Mandar Maju

Sekaran, U., dan Bougie (2010), Research Methods for Busines. A Skill Building Approach. Fifth Edition. A John Wiley and Sons, Ltd, Publication.

Siagian, Sondang. (2013). Manajemen Sumber Daya Manusia (cetakan 15). Jakarta: Bumi Aksara

Sink, R dan Tuttle, J.K. (1989). Evaluasi Kinerja. Jakarta: Indeks Kelompok Gramedia.

Smithson, Janet., Suzan Lewis (2013). Is job insecurity changing the psychological contract. Personnel Review ,29(6):1-15
Sri Isworo Ediningsih, Wisnalmawati Wisnalmawati (2009), Pengaruh Kematangan Karyawan Dengan Gaya Kepemimpinan Situasional Pengusaha Perempuan Sebagai Variabel Moderating Terhadap Kinerja Karyawan, Jurnal Analisis Bisnis Ekonomi, Vol. 7 No. 1

Sugiyono. (2009). Metode Penelitian Kuantitatif dan Kualitatif dan R \& D. Bandung : Alfabeta

Suryana Sumantri (2013). Perilaku Organisasi. Bandung: Universitas Padjadjaran

Sutrisno, Edy (2014). Manajemen Sumber Daya Manusia, Kencana Prenada Media Group Jakarta

Thoha, Miftah. (2001). Birokrasi Indonesia Dalam Era Globalisasi, Pusdiklat Pegawai Depdiknas, Sawangan, Bogor.

Terry George dan Rue, Leslie W alih bahasa Sadeli (2011), Dasar-Dasar Manajemen, Cetakan Ketujuh Bumi Aksara Jakarta.

Triton PB (2015), Paradigma Baru Manajemen Sumber Daya Manusia, Tugu Yogyakarta. (2006), SPSS 12.00 Terapan Riset Statistik Parametrik, Andi Yogyakarta.

Tri Widari (2016), Pengaruh Disiplin dan Lingkungan Kerja Terhadap Kinerja Pegawai BKD Daerah Istimewa Jogjakarta, Tesis UNY

Yukl, G. (2013). Kepemimpinan Dalam Organisasi.Edisi Indonesia (kelima). Cetakan kedua. Penerbit PT Indeks, Jakarta. 